\title{
Knowledge acquisition development in failure diagnosis analysis as an interactive approach
}

\author{
Mohammad Yazdi ${ }^{1}$ (1) $\cdot$ Hamzeh Soltanali ${ }^{2,3}$
}

Received: 19 June 2018 / Accepted: 6 July 2018

(c) Springer-Verlag France SAS, part of Springer Nature 2018

\begin{abstract}
Safety and reliability analysis is an important issue to prevent an event which may to occurrence of catastrophic accident in process industries. In this context, conventional safety and reliability assessment technique like as fault tree analysis have been widely used in this regards; however, they still suffer in subjective uncertainty processing and dynamic structure representation which are important in risk assessment procedure. In this paper, a new framework based on 2-tuple intuitionistic fuzzy numbers and Bayesian network mechanism is proposed to evaluate system reliability, to deal with mentioned drawbacks, and to recognize the most critical system components which affects the system reliability. The reliability and safety guarantee of such system in the aspect of continuity operations and enhancing the safety of operators and vehicle drivers are crucial. The results revealed that the proposed model could be useful for diagnosing the systems' faults compared with listing approaches of safety and reliability analysis.
\end{abstract}

Keywords Tactic knowledge $\cdot$ Fault tree $\cdot$ Interval 2-tuple $\cdot$ Dependency $\cdot$ Automotive industry

\section{Introduction}

With the current technological complexity of modern systems, the product reliability constitutes the significant attribute to satisfy the demand and increase the quality toward sustainable production [1]. To satisfy the demand and increase the quality of life for human beings, the product reliability is an indispensable factor both on the academic research and practice. In real world, high tech industry is more complicated systems and to analyze such these industries, fault tree analysis (FTA) as a powerful diagnosis and risk assessment technique is usually used based on reliability, maintenance, and experts systems knowledge [2,3].

Mohammad Yazdi

mohammad.yazdi@tecnico.ulisboa.pt

Hamzeh Soltanali

hamzeh.soltanali@ltu.se

1 Centre for Marine Technology and Ocean Engineering (CENTEC), Instituto Superior Técnico, Universidade de Lisboa, Lisbon 1049-001, Portugal

2 Division of Operation and Maintenance Engineering, Luleå University of Technology, Luleå, Sweden

3 Department of Biosystems Engineering, Ferdowsi University of Mashhad, Mashhad, Iran
Expert systems development is an unavoidable issue in risk assessment procedure in varieties of fields like as science, engineering, and medicine. It is commonly engaged to solve the relevant problems of experts' fields focusing on the intellectual programing system. In addition, it is using the experience besides knowledge which employed experts accumulated for many years. Employing expert system has been classified by apprehending expert knowledge in case of a possibility for non-experts to solve a specific problem by previous knowledge captured and stored in the computer [4]. In development of an expert system, two key issues play significant rule which are acquisition of domain experts' professional knowledge and representation/reasoning of the transformed knowledge. In recent years, many knowledge representation methods have been developed; however, regarding to the increasing complexity of today's knowledge-based systems, remarkable effort has to been paid to the improvement of knowledge acquisition [4-10]. Further, the typical knowledge acquisition process is to obtain the knowledge directly by the engineer knowledge through interactions with experts $[11,12]$.

In general, the knowledge is divided in two categories including tactic and explicit knowledge, which the latter one firstly was introduced by Polanyi [13] and have been widely used in bulk literature studies [14-16]. Explicit knowledge 
is known as codified and organized knowledge, meaning that it can be transferred into the figures, words, and numbers. Explicit knowledge is also named objectivity which is easy to share in the symptom of reports, data, and standard operating procedure. In the opposite side, tactic knowledge is the knowledge staying in the head of experts which is confidential and highly difficult to be codified. It can be called as subjective and unstructured knowledge. Tactic knowledge is obtained in a period of time under perception, reproduction, and experience. For a long time, decision makers mainly focus on explicit and objective knowledge because of easily handling and sharing. However, this attitude to use explicit knowledge makes it important for practice and academia to determine the ignored opportunities which might result from missed tactic and subjective knowledge; besides, there is no possibility that knowledge acquisition in completed in a group of decision makers on an individual basis [17-23]. Tacit knowledge is established personally and depends on individual experience, perceptions, and insights while in an expert system, decision makers are willing to use the linguistic terms for representing their judgments. Obviously, in a group of experts, each of them has varying opinions according to their different background and experience. Additionally, experts are usually uncertain of their estimations in knowledge acquisition process because of many reasons such as limitation of time, absence of experience and data. In this context, fuzzy set theory introduced by Zadeh [24] can be utilized to handle tactic knowledge. With respect to the advantages of fuzzy set theory, but some of which may be unclear, ambiguous, incomplete, or even uncertain $[16,25]$. The information is hardly to integrate into the tacit knowledge acquisition by using existing conventional fuzzy set theory. However, in a parallel way, uncertainty treatment [26] can be utilized as a significant issue in knowledge acquisition procedure which is not the main goal of this study.

In safety concept, in experts systems, two significant issues as a main part of any risk assessment procedure are identified which are representation of knowledge and acquisition of domain experts. Firstly, as a promising tool for knowledge representation and reasoning in risk assessment; like as FTA and even more conventional fuzzy FTA still suffer a couple of deficiencies. As an example, the available rules in the most existing knowledge inference frameworks will not be able to dynamically changeable based on propositions' variation as human cognition and thinking. Furthermore, the parameters in conventional fuzzy FTA models cannot exactly signify the increasingly complex knowledge-based systems. Secondly, due to the expert knowledge acquisition process, the domain expert board usually establishes diverse experience and knowledge from one another and produces various types of knowledge information including complete/incomplete, precise/imprecise, and known/unknown because of its cross functional and multidisciplinary nature [18, 19]. The latter shortages can be handled by the interval 2-tuple linguistic terms method. The 2-tuple intuitionistic fuzzy numbers (IFNs) and many of its considerable extension can overcome on aforementioned limitation [27]. The significant superiority of IFNs are that the experts can express their opinions using 2-tuple linguistic term with diversity of uncertainty and ambiguities, the numerous uncertainties in the judgments can be modeled by using IFNs [28, 29]. The 2-tuple IFNs and its current extension have been widely used to solve many multi-criteria decision making (MCDM) problem. Currently, a hybrid method based on integration of analytical network process (ANP) and ELECTRE II methods in interval 2-tuple linguistic environment for supplier selection is conducted by Wan et al. [30]. In another study, Singh et al. [31] developed the PROMETHEE II method to interval-valued 2-tuple linguistic variables in order to address energy planning problems. In a same way, Liu et al. [25] cope with the problems of robot selection using an interval 2-tuple linguistic MCDM method. Shan et al. [32] developed some interval 2-tuple linguistic harmonic mean operators and their application in material selection followed by Lin et al. [33] used a new interval linguistic aggregation operator for facility location selection based on optimal aggregation technique. In risk assessment context, Bozdag et al. [34] ranked the failure modes in Failure Mode and Effects Analysis (FMEA) technique using an interval type-2 fuzzy sets. Further, Liu et al. [35] applied intuitionistic fuzzy hybrid TOPSIS approach to prioritize the identified failure modes concerning a 1.8-in. color super twisted nematic. Yazdi [36] introduced a novel 2tuple intuitionistic fuzzy-hybrid-modified TOPSIS approach for assessing hazards in a gas refinery for the welding and lamination task to represent the effectiveness and reliability of proposed model to compare with the conventional risk matrix. Therefore, the model based on the interval 2-tuple linguistic terms method will be more flexible and precise to cope with expert judgments in the tacit knowledge acquisition process.

However, to the best of authors knowledge, there are few attempts have been done to use 2-tuple linguistic terms in FTA, whereas many studies have been performed using conventional fuzzy FTA like as [36, 37]. As a prior study, an intuitionistic fuzzy sets based method has been engaged for the failure analysis of the printed circuit board assembly [38]. Authors directly compute the intuitionistic fuzzy FT interval, traditional reliability, and the intuitionistic fuzzy reliability interval and Chang et al. [39] introduced an algorithm of vague FTA to compute fault interval of system components from integrating expert's knowledge. Cheng et al. [40] proposed an intuitionistic FTA procedure to compute the intuitionistic fuzzy reliability interval for liquefied natural gas terminal emergency shutdown system. Kumar and Yadav 
[41] applied the weakest t-norm based intuitionistic fuzzy FT analysis to evaluate system reliability by finding the most critical system component that affects the system reliability. Therefore, one of the main objectives of this research is proposed tactic knowledge acquisition framework using 2tuples interval linguistic terms and fuzzy Fuzzy Analytical Hierarchy Process (FAHP) in order to capture, store, share, leverage, and improve tactic knowledge based on increasing and sustaining in competitive advantages of experts' knowledge in FTA.

In the other hand, to deal with dynamically changeable (first shortages), Bayesian network (BN) mechanism can be utilized to handle this lack in conventional FTA. BN as a well-known graphical model illustrates the causal relationships between key factors (causes) and one or more final outcomes in a system. BN analysis may be qualitative, quantitative, or both, depending on the scope of the analysis as well as FTA and it is popular in statistics, machine learning, artificial intelligence, and risk and reliability analyses [42]. Additionally, BN has also been widely applied in numerous risk and reliability studies [43-46], improving the safety performance of a system [47-50], updating failure probability [51-53], mapping static or dynamic FTs into corresponding BNs [54-58], and in recent work combining $\mathrm{BN}$ and petri nets aimed to analyze dynamic safety system [59].

Regarding to our definition and sight of the concept of "Interactive approach" and the first asked question as "Are the models being used being the origin of the interactivity?", some changes have been made in the article and following text is added to introduction part:

Besides of above-mentioned issues, FTA method is deeply based on decision making process which can be divided into the interaction level with the decision makers. There are such methods that do not obtain the decision makers preference information like as neutral compromise solution, whereas there are interactive methods like as reference point approaches in which the decision makers is asked for preference information at each iteration. The concept of interactive approach in decision making process is a hands-on and a realworld approach. It helps assessors during risk assessment procedure being more engaged and retain more material, with or without a form of technology. Interactive FTA method assistances assessors reinforce problem-solving and critical thinking skills. Among two common mentioned approaches, the former obtains the decision makers preference information before generating alternatives, whereas the latter gathers the decision maker's preference information after generating alternatives. In some studies, 'no preference' and 'a posteriori' methods are classified as 'generating methods', and 'a priori' and 'interactive' methods are classified as 'preference based methods'. Thus, in this study, because of an interactive approach due to decision making procedure is introduced and utilized to improve FTA with consideration of uncertainty handling $[60,61]$.

The main purpose of this paper is to provide new framework to improve knowledge acquisition for analyzing fault diagnosis in a FT and comparing the results with listing of approaches. In the next section, a new framework based on interval 2-tuple IFNs is presented to compute the failure probability (FP) of the top event (TE) in FTA. Firstly, a new knowledge acquisition technique based on interval 2-tuples and FAHP is introduced to model the variety and vagueness of knowledge information in tacit knowledge acquisition. Secondly, BN is used to handle the lack of conventional FTA either in a crisp or fuzzy environment. In Sect. 3 , the practicality and usefulness of the proposed approach is demonstrated by a numerical example in an automotive manufacturing process fault. The concluding remarks and recommendation for further studies are presented in the last section.

\section{Methodology}

As it can be seen from Fig. 1, a new framework is proposed to improve the knowledge acquisition in failure diagnosis analysis. Expert judgment, modeling, and calculation are the three key stages in the proposed model. Once an event is selected as a TE; accordingly, the modeling part using FTA and BN is constructed and developed. Next, a group of employed experts express their opinions for possibility of each basic event (BE) using linguistic terms. A reliable aggregation process is applied, which collects all possibilities in terms of linguistic opinions. Applying the aggregation result, the probability of each $\mathrm{BE}$, and subsequently $\mathrm{TE}$ is computed. Finally, critical BE is identified to obtain further corrective actions to reduce the probability of TE. The details of each stage are provided as follows.

\subsection{Developing fault tree analysis}

Fault tree (FT) is an effective graphical tool commonly used in process risk accident analysis [62-64]. A FT is a top-down logic diagram that illustrates the interrelationships between a potential critical event in a system and the causes of this event. In the diagram, the causes at the lowest level are named BEs and may be component failures, environmental conditions, human errors, and normal events (i.e., events that are expected to occur during the life span of the system) [65]. FTA is a deductive method meaning that the reason backward in the contributing arrangement of a specific event. It is started with a specified potential critical event in the system, named the TE of the FT. The BEs either alone or in combination using intermediate event (IEs) lead to the TE are identified and linked using logical AND/OR gates to the TE [66]. All BEs, from the TE to the down are supposed to be 
International Journal on Interactive Design and Manufacturing (IJIDeM)

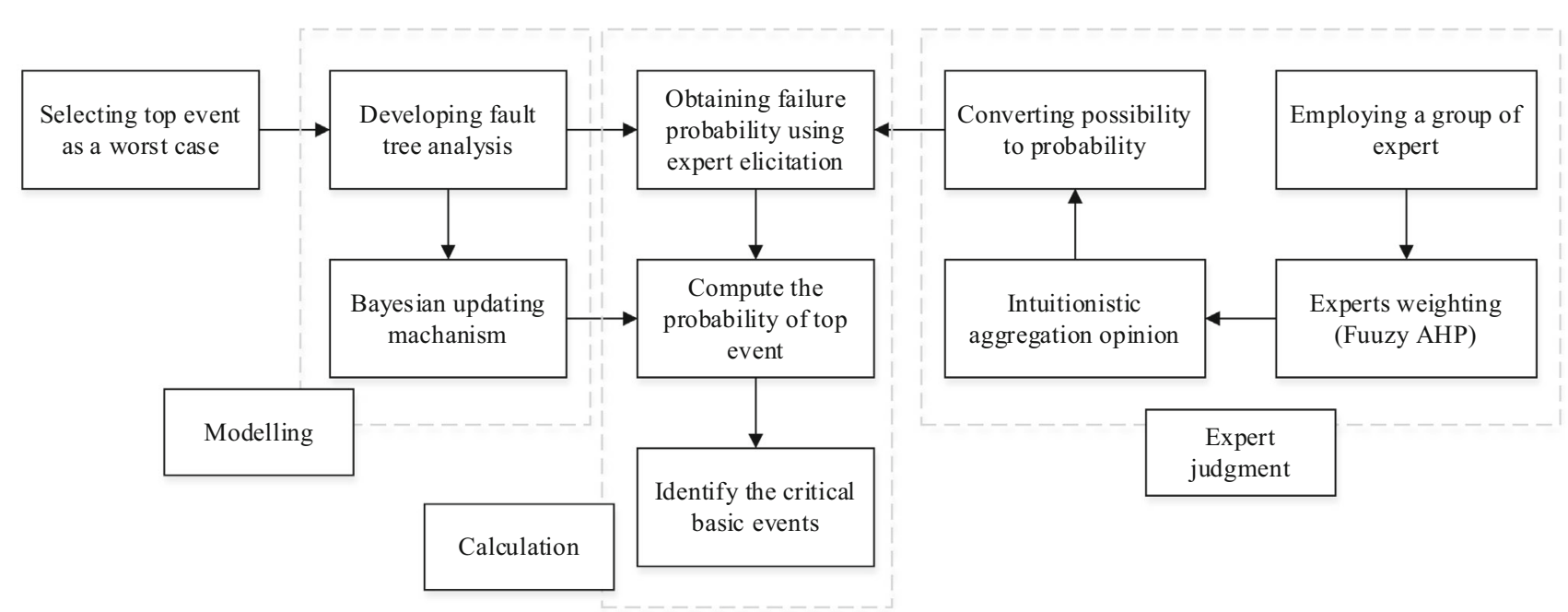

Fig. 1 The proposed framework

binary events that either occur or do not occur, which means that FTA is also deterministic method. In other words, once a FT is developed and all the states of the BEs are known, the TE and the states of all IEs are also known. This procedure is continued deductively until a suitable level of detail is reached $[67,68]$. To compute the probability of TE in a quantitative analysis, following conventional assumptions and mathematical operations can be performed:

$$
\begin{aligned}
& P_{O R}=1-\prod_{i=1}^{n}\left(1-P_{i}\right) \\
& P_{A N D}=\prod_{i=1}^{n} P_{i}
\end{aligned}
$$

Once the probability of each $\mathrm{BE}$ as an input data is known, accordingly the probability of TE can be computed. Input data for BE are divided in five categories including nonrepairable component, repairable component, periodically tested component, frequency, and on-demand probability in this regards; however, the computation based on each categories are different. However, in the FTA sometimes there is lack of information to obtain failure rate for all BEs. Therefore, three other ways like as expert judgment, extrapolation, and statistical may be engaged as a trustworthy alternative way. In this study, expert judgment is used for to compute the probability of all BEs.

\subsection{Bayesian updating mechanism}

A Bayesian network (BN) is a graphical model which shows the causal relationships between causes and one or more final outcomes in a system. Known as an interface probabilistic method, BN made up of nodes and directed arcs in an interface probabilistic method. A node describes a state or condition, an arc indicates a direct influence, and probability tables to represent a set of random variables and the conditional dependency among them. Probabilities can be inserted into the $\mathrm{BN}$ in order to find the probability of the outcome; same as FT. The flexibility of BN structure and its probabilistic reasoning engine has enough capability for risk analysis in the large and complex systems [51, 57, 58, 69-74]. In a BN model, both forward and backward analysis could be performed. A forward analysis is accomplished to estimate the probability of unknown variables by following the arcs of the network. On the other hand, the backward analysis is performed by following the network arcs in opposite direction to update the probability of known variables based on some evidence [75].

Assuming the conditional dependencies of variables, BN shows the joint probability distribution $P(U)$ :

$P(U)=\prod_{i=1}^{n-1} P\left(X_{i} \mid X_{i+1}, \ldots X_{n}\right)$

where $U=\left\{X_{1}, X_{2}, \ldots, X_{n}\right\}$ and $X_{i+1}$ is the parent of $X_{i}$. Accordingly, the probability of $X_{i}$ can be computed as:

$P\left(X_{i}\right)=\sum_{U \backslash X_{i}} P(U)$

The main advantage of $\mathrm{BN}$ is in a probability updating. This information is commonly based on expert knowledge or becomes available in the lifecycle of processes, such as accidents, incidents, near misses, mishaps, etc. Based on Bayes theorem, $\mathrm{BN}$ can be used to update the prior probability of an event $(E)$, explanation the updated or posterior probabilities:

$P(U \mid E)=\frac{P(U \cap E)}{P(E)}=\frac{P(U \cap E)}{\sum_{U} P(U \cap E)}$ 
To obtain more information once can refer to the Jensen and Nielsen [47].

\subsection{Expert judgment}

Expert knowledge is affected by individual visions and purposes [76]. Therefore, it is very difficult to assess the complete impartiality of expert knowledge. The main challenge is the selection of heterogeneous specialists (e.g., either scientists or workers) and homogenous specialists (it just includes scientists).

Individual experience on expert judgment is presumed to be smaller in the homogeneous group as compared to the heterogeneous one as a result of experience differences. Therefore, by considering all possible opinions, a group of heterogeneous specialists could have a privilege over the homogeneous group. Moreover, the weights of experts are different, so in real life, the heterogeneous group is more realistic $[77,78]$. The criteria for the recognition of experts are established as follows; firstly, the period of learning and experience in the precise scope of knowledge. Secondly, the individual conditions in which experience is obtained, including either practical or theoretical conditions are considered. Thus, using the FAHP method can handle this problem. Accordingly, each expert is evaluated based on the four criteria: education, job tenure, experience, and age. FAHP as a first preliminary is explained as follows.

Preliminary 1 Fuzzy Analytical Hierarchy Process (FAHP).

Conventional AHP as a well-known method is widely used in multi-criteria decision making issues. AHP originally is introduced by Saaty (2010) [79] to deal with the complexity of decision problems using hierarchy of decision layers. Due to the breaking the problem into the several layers and unable to subjective practical approach (capability of reflecting the human thinking), hence, the FAHP has been developed to solve the AHP problems [80]. Additionally, the subjectivity should be avoided in order to achieve more credible and reliable results [75]. In this regards, the main extension of the FAHP techniques under trapezoidal and triangular memberships are introduced by $[81,82]$.

Stage 1 let $\tilde{a}_{i j}^{k}=\left(\tilde{a}_{i j 1}^{k}, \tilde{a}_{i j 2}^{k}, \tilde{a}_{i j 3}^{k}\right), \quad(i=$ $1,2, \ldots,(n-1), j=2,3, \ldots, n)$ be the fuzzy relative importance by comparing criterion $i$ with criterion $j$ provided by kth expert. Then, the aggregated fuzzy relative importance $\tilde{a}_{i j}$ is obtained as follows.

$\tilde{a}_{i j}=\left(\sum_{k=1}^{K} \lambda_{k} \cdot \tilde{a}_{i j 1}^{k}, \sum_{k=1}^{K} \lambda_{k} \cdot \tilde{a}_{i j 2}^{k}, \sum_{k=1}^{K} \lambda_{k} \cdot \tilde{a}_{i j 3}^{k}\right)$

where $\lambda>0(k=1,2, \ldots K)$ and satisfying $\sum_{k=1}^{K} \lambda_{k}=1$.
Stage 2 Pairwise comparison matrices are made in the dimensions of the hierarchy procedure throughout all the defined criteria. Experts' opinions in quantifiable terms are allocated by considering the importance of pairwise comparison.

$\tilde{A}=\left[\tilde{a}_{i j}\right]=\left[\begin{array}{cccc}1 & \tilde{a}_{12} & \cdots & \tilde{a}_{1 n} \\ 1 / \tilde{a}_{21} & 1 & \cdots & \tilde{a}_{2 n} \\ \vdots & \vdots & \ddots & \vdots \\ 1 / \tilde{a}_{n 1} & 1 / \tilde{a}_{n 2} & \cdots & 1\end{array}\right]$

when criterion $i$ is of relative importance to criterion $j$, $\tilde{a}_{i j}=\tilde{1}, \tilde{3}, \tilde{5}, \tilde{7}, \tilde{9}$. In contrast, when criterion $j$ is of relative importance to criterion $i, \tilde{a}_{i j}=\tilde{1}, \tilde{3}^{-1}, \tilde{5}^{-1}, \tilde{7}^{-1}, \tilde{9}^{-1}$. In a situation $i=j, \tilde{a}_{i j}=1$.

Where relative importance criterion $j$ in qualitative terms and corresponding fuzzy numbers are provided in Fig. 2 and Table 1 as follows.

Stage 3 Examine the consistency of fuzzy pairwise comparison matrix. Considering $A=\left[a_{i j}\right]$ as a positive mutual matrix and $\tilde{A}=\left[\tilde{a}_{i j}\right]$ is a fuzzy positive mutual matrix. As it discussed in [81], if $A=\left[a_{i j}\right]$ is consistent, $\tilde{A}=\left[\tilde{a}_{i j}\right]$ will also be consistent. Thus, this study used this procedure to examine the consistency of comparison matrix and validate the questionnaire provided for experts. In case the inconsistency of the comparison matrix, the evaluation procedure should be repeated to improve the consistency [20].

Stage 4 Using the geometric mean method, the fuzzy weights of fuzzy comparison values between criteria is calculated by Eq. (8) as follows.

$\tilde{r}_{i}=\left(\tilde{a}_{i 1} \otimes \tilde{a}_{i 2} \otimes \cdots \otimes \tilde{a}_{i n}\right)^{1 / n}$

where $\tilde{a}_{i n}$ is a fuzzy comparison values of criterion $i$ to criterion $n$.

Stage 5 For each criterion, the fuzzy weights are defined as follows.

$\tilde{w}_{i}=\tilde{r}_{i} \otimes\left(\tilde{r}_{1} \oplus \tilde{r}_{2} \oplus \cdots \oplus \tilde{r}_{n}\right)^{-1}$

$\tilde{w}_{i}$ is defined as a fuzzy weight of criterion $i$ and $\tilde{w}_{i}=$ $\left(l \tilde{w}_{i}, m \tilde{w}_{i}, u \tilde{w}_{i}\right)$ which are included $l \tilde{w}_{i}, m \tilde{w}_{i}$, and $u \tilde{w}_{i}$ justify the lower, middle and upper value of the fuzzy weights of criterion $i$, respectively.

Stage 6 Defuzzification procedure. The significant step in fuzzy multi-criteria decision making is defuzzification procedure which locates the best non-fuzzy performance (BNP) value. There are many technique are available for defuzzification including center of area (CoA), mean of maximum (MoM), and $\alpha-c u t$. CoA is known as a more simple and 


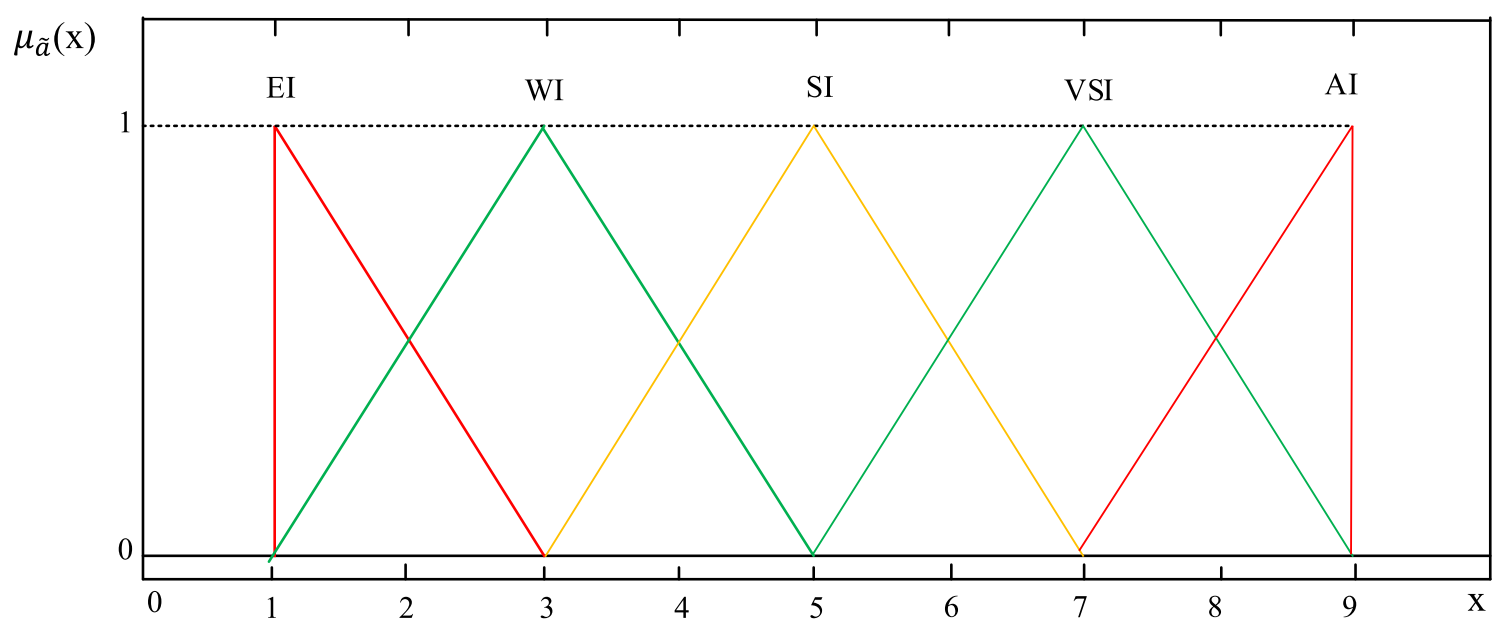

Fig. 2 Membership function for pairwise comparison importance of criterion $j$

Table 1 The fuzzy corresponding number for relative importance comparison to criterion

\begin{tabular}{lll}
\hline Fuzzy number & Qualitative terms & $\begin{array}{l}\text { Triangular fuzzy } \\
\text { number }\end{array}$ \\
\hline$\tilde{9}$ & Absolutely important (AI) & $(7,9,9)$ \\
$\tilde{7}$ & Very strongly important (VSI) & $(5,7,9)$ \\
$\tilde{5}$ & Strongly important (SI) & $(3,5,7)$ \\
$\tilde{3}$ & Weakly important (WI) & $(1,3,5)$ \\
$\tilde{1}$ & Equally important (EI) & $(1,1,3)$ \\
$\tilde{3}^{-1}$ & Weakly unimportant (WU) & $(1 / 5,1 / 3,1)$ \\
$\tilde{5}^{-1}$ & Strongly unimportant (SU) & $(1 / 7,1 / 5,1 / 3)$ \\
$\tilde{7}^{-1}$ & Very strongly unimportant & $(1 / 9,1 / 7,1 / 5)$ \\
& (VSU) & $(1 / 9,1 / 9,1 / 7)$ \\
$\tilde{9}^{-1}$ & Absolutely unimportant (AU) &
\end{tabular}

practical technique; therefore, it is used to compute the BNP value of the fuzzy weights of each dimension.

$X^{*}=\frac{\int v_{i}(x) x d x}{\int v_{i}(x) d x}$

where $X^{*}=$ Defuzzified output; $v_{i}(x)=$ Aggregated membership function; $x=$ output variable.

Defuzzification of triangular fuzzy number $\tilde{A}=\left(\mathrm{a}_{1}, \mathrm{a}_{2}\right.$, $\left.\mathrm{a}_{3}\right)$ is:

$X^{*}=\frac{\int_{a_{1}}^{a_{2}} \frac{x-a_{2}}{a_{2}-a_{1}} x d x+\int_{a_{2}}^{a_{3}} \frac{a_{3}-x}{a_{3}-a_{2}} x d x}{\int_{a_{1}}^{a_{2}} \frac{x-a_{2}}{a_{2}-a_{1}} d x+\int_{a_{2}}^{a_{3}} \frac{a_{3}-x}{a_{3}-a_{2}} d x}=\frac{1}{3}\left(a_{1}+a_{2}+a_{3}\right)$

where $X^{*}$ is the weight on expert $j$.

In this study, a heterogeneous group of experts expresses their opinions for possibility of each BE in linguistic terms. As it mentioned earlier, the linguistic terms are defined as
IFNs because of improving knowledge acquisition. IFS is explained as a second preliminary as follows.

Preliminary 2 Intuitionistic fuzzy set (IFS).

Atanassov (1986) [83] presented Intuitionistic fuzzy set (IFS) to deal acceptably with ambiguity as an extension of the classical model introduced by Zadeh [24] which includes the membership and non-membership functions and hesitation margin groups. Xu (2011) [84] indicated that the IFS data are more comprehensive than the fuzzy conventional set with only a membership function. Chang and Cheng, (2010), Chang et al. (2010) [85, 86] showed that IFS is a proper approach to deal with ambiguities and uncertainties in failure mode and effect analysis (FMEA) as an efficient risk assessment technique. Figure 3 illustrates the interrelations among crisp sets, fuzzy sets, and IFS. The definition of IFS and the related issues are provided as follows [87, 88]:

Definition 1 Considering $X$ as a fixed set, intuitionistic fuzzy $S$ in $X$ is introduced:

$S=\left\{\left\langle x, \mu_{S}(x), v_{S}(x)\right\rangle \mid x \in X\right\}$,

where $\mu_{S}(x)$ and $v_{S}(x) \in[0,1]$ are denoted as a degree of membership and non-membership functions, respectively, and satisfy $0 \leq \mu_{S}(x)+v_{S}(x) \leq 1, \forall x \in X$.

In addition, the hesitation degree of $x \in S$ indicates the degree of uncertainty of $x$ to $S$ and is given as $\pi_{S}(x)=1-$ $\mu_{S}(x)-v_{S}(x)$, and clearly satisfies $0 \leq \pi_{S}(x) \leq 1, \forall x \in X$.

It is obvious that the value of $x$ is more uncertain or certain when the value of $\pi_{S}(x)$ is large or small, respectively. Moreover, as illustrated in Fig. 4 considering both continuous functions of $\mu_{S}(x)$ and $v_{S}(x)$, IFS clearly regresses the conventional fuzzy set when $\mu_{S}(x)=1-v_{S}(x)$. In addition, IFS reduces into a crisp set in special cases when the value of $\mu_{S}(x)=1-v_{S}(x)$ is equal to 0 or 1 . 


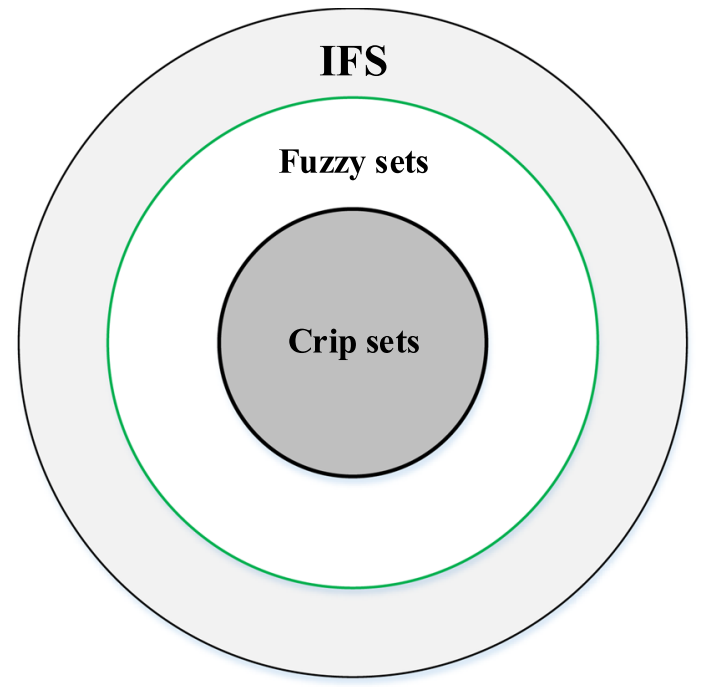

Fig. 3 Interrelations between crisp sets, fuzzy sets and IFS [89]

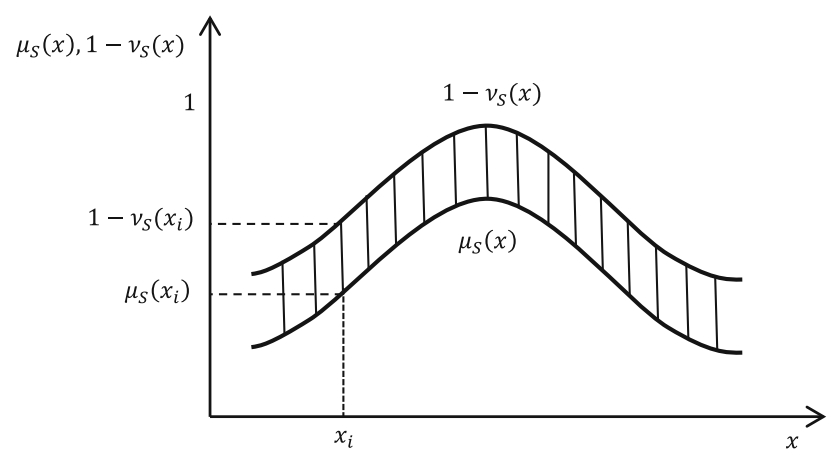

Fig. 4 Intuitionistic fuzzy sets [90]

The set $\left(\mu_{S}(x), v_{S}(x)\right)$ is called an intuitionistic fuzzy number in IFS and $\alpha=\left(\mu_{S}(x), v_{S}(x)\right)$ simply represents each IFN, where $\mu_{\alpha} \in[0,1]$ and $v_{\alpha} \in[0,1]$, and also satisfies $\mu_{\alpha}+v_{\alpha} \leq 1$. It should be noted that for an IFN $\alpha=\left(\mu_{\alpha}, v_{\alpha}\right), \alpha^{+}(1,0)$ and $\alpha^{-}(0,1)$ are nominated as the largest and smallest IFNs, respectively.

Definition 2 Let $\alpha_{1}=\left(\mu_{\alpha_{1}}, v_{\alpha_{1}}\right)$ and $\alpha_{2}=\left(\mu_{\alpha_{2}}, v_{\alpha_{2}}\right)$ be two IFNs, and the intuitionistic fuzzy distance (IFD) between $\alpha_{1}$ and $\alpha_{2}$ is illustrated as follows:

$d_{I F D}\left(\alpha_{1}, \alpha_{2}\right)=\left|\alpha_{1}-\alpha_{2}\right|=\frac{1}{2}\left(\left|\mu_{\alpha_{1}}-\mu_{\alpha_{2}}\right|+\left|v_{\alpha_{1}}-v_{\alpha_{2}}\right|\right)$

The next stage of the procedure presents the aggregation of experts' opinions in an intuitionistic fuzzy environment.

\subsection{Aggregation procedure}

According to IFS, the linguistic terms are defined as intuitionistic fuzzy numbers (IFNs) that are presented in Table 2
Table 2 Rating for possibility of each BE

\begin{tabular}{ll}
\hline Linguistic terms & IFNs \\
\hline Extremely low (EL) & $(0.10,0.90)$ \\
Very low (VL) & $(0.25,0.70)$ \\
Low (L) & $(0.30,0.60)$ \\
Fairly low (FL) & $(0.40,0.50)$ \\
Medium (M) & $(0.50,0.50)$ \\
Fairly high (FH) & $(0.60,0.30)$ \\
High (H) & $(0.70,0.20)$ \\
Very high (VH) & $(0.75,0.20)$ \\
Extremely high (EH) & $(0.90,0.10)$ \\
\hline
\end{tabular}

for the possibility of each BE. The theoretical basis for the transformation between linguistic terms and IFNs in Table 2 are provided in details by Liu et al. (2014) [60] and subsequently the detail reasons of why linguistic terms can be defined as IFNs are provided by Zhao (2016) [91, 92]. Thus, the employed experts express their opinion due to the possibility of occurrence foe each BE using IFNs.

In recent years, $\mathrm{Xu}$ (2007) [93] has introduced an extension of the intuitionistic fuzzy-hybrid-weighted Euclidean distance (IFHWED) operator to aggregate experts' opinions and order them when the linguistic terms are prepared with IFNs. IFHWED is integrated with the intuitionistic fuzzy-weighted Euclidean distance (IFWED) operator and the intuitionistic fuzzy-ordered-weighted Euclidean distance (IFOWED) operator, and both IFWED and IFOWED are developed by Zeng (2012) [94]. The principal superiority of IFHWED is that it cannot only integrate both of them by applying the degree of importance but can also reduce the effect of unreasonable small (or large) deviations on the aggregation outcomes by allocating them in different weights. The steps of aggregation procedure which is engaged in this study are provided as follows.

Aggregate the expert's opinion using the intuitionistic fuzzy weighted averaging (IFWA) operator for any BEs, $\mathrm{BE}_{i}=(i=1, \ldots, m)$.

$$
\begin{aligned}
\alpha_{i j} & =\operatorname{IFWA}\left(\alpha_{i j}^{1}, \alpha_{i j}^{2}, \ldots, \alpha_{i j}^{n}\right)=\sum_{k=1}^{n} \lambda_{k} \alpha_{i j}^{k} \\
& =\left[1-\prod_{k=1}^{n}\left(1-\mu_{i j}^{k}\right)^{\lambda_{k}}, \prod_{k=1}^{n}\left(v_{i j}^{k}\right)^{\lambda_{k}}\right]
\end{aligned}
$$

where $\alpha_{i j}=\left(\mu_{i j}, v_{i j}\right)$ is the final aggregated subjective opinions in terms of IFN, $\alpha_{i j}^{k}=\left(\mu_{i j}^{k}, v_{i j}^{k}\right)$ is the IFN that is transferred by the corresponding linguistic terms according to an experts' opinion, $\lambda_{k}$ is the given weight to each expert according to fuzzy AHP that represents the importance of 
his/her opinion on $\mathrm{BE}_{i}$, and satisfies $\lambda_{k}>0(k=1, \ldots, n)$ and $\left(\sum_{k=1}^{n} \lambda_{k}=1\right)$.

Next, to make reliable decisions with consideration of maintenance actions, the intuitionistic fuzzy output is converted into the crisp value using Eq. 13. However, Boran et al. (2009) [95] showed that Eq. 14 can be normalized to Eq. 15. Additionally, Anzilli and Facchinetti (2016) [96] represented that, Eq. 15 can be considered as a defuzzification IFNs which obtained by:

$\operatorname{Val}_{S}(x)=\frac{1}{2} \times\left(1+\mu_{S}(x)-v_{S}(x)\right)$

\subsection{Computing the failure probability of BE and TE}

Once the crisp value as a possibility of an input event (BE) is computed then the possibility is converted to probability using Onisawa equations as follows [97, 98].

$$
F P=\left\{\begin{array}{ll}
1 / 10^{K}, & C F P \neq 0 \\
0, & C F P=0
\end{array}, \quad K=\left[\left(\frac{1}{\mathrm{CFP}}-1\right)\right]^{1 / 3} \times 2.301\right.
$$

where FP is denoted as failure probability of each BE and CFP is signifies as corresponding crisp failure possibility extracted using IFS.

In order to compute the probability of TE, Eqs. 1-2 and Boolean algebra in FTA model and Eqs. 3-5 in BN model are utilized.

\subsection{Identifying the critical BEs}

For this purpose, several importance measures (IMs) have been developed to measure the relative importance of a $\mathrm{BE}$, to compare with other BEs, regarding to the TE [99]. To obtain the IMs of each BE, two different sources is necessary to be considered. Firstly, the probability of the BE and secondly, the place of BE in FTA. Therefore, IMs help to determine how much the TE probability changes when one or more input parameters are changed. This information could assist as a valuable source of data for resource allocation such as upgrade, maintenance, and etc. and helps stakeholders in improving system dependability including safety, reliability, availability, and etc. [59]. In conventional FTA, different IMs such as Birnbaum importance measures (BIM), Fussel-Vesely importance measures, and Risk Reduction Worth (RRW) [100] are widely used. Cheok et al. (1998) [101] presented how these different measures can be computed. In this paper, BIM as a significant tool in IMs is used. It is obtained by partial differentiation of the TE probability with respect to probability of each $\mathrm{BE}$ and signifies a classical sensitivity measure. If $\mathrm{I}_{\mathrm{BE}_{\mathrm{i}}}^{\mathrm{BIM}}$ is large, a small change in probability of $\mathrm{BE}$ will leads to a comparatively large change in the TE probability. Let $P\left\{T E \mid B E_{i}\right\}$ and $P\left\{T E \mid B E_{i}^{*}\right\}$ be the conditional probability of the TE, when it is known that basic event $i$ has occurred $B E_{i}$ and not occurred $B E_{i}^{*}$, respectively [102]. In our proposed framework, it is used the BIM of BEs as follows:

$$
I_{B E_{i}}^{B I M}=P\left(T E \mid B E_{i}\right)-P\left(T E \mid B E_{i}^{*}\right)
$$

Based on BIM, first, the TE probability $P\left(T E \mid B E_{i}\right)$ is computed by assuming that basic event $i$ has occurred. Then, the TE probability $\left(T E \mid B E_{i}^{*}\right)$ is computed when it is assumed that the BE has not occurred.

\section{Empirical case study}

In order to implement the proposed framework, a fluid filling system as the most critical and complex equipment in an automotive production process was evaluated. The reliability and safety guarantee of such system from operational and non-operational aspects are important. Considering the former, because of the importance of speedy nature in various operations, a low reliability leads to an increase in operational costs and equipment breakdown, and ultimately a downtime in the assembly lines. Speaking of the latter, an effective management of fluid filling system through the reducing the risk of unexpected events can enhance the safety of operators and vehicle drivers. Figure 5 shows the outer (a) and inner (b) views of the fluid filling system and its process description (flow diagram). The system takes care of leakage test through producing pressure and vacuum as well as filling/charging and leveling different fluids in paths and pipes of vehicles. The fluid volume varies in different vehicles, based on the existing standards. The most important feature of the system is simultaneous activity of many devices in different blocks. In other words, any failure of a component in each block leads to not only system disability but downtime in the whole production line.

Figure 6 displays a scheme of the fluid filling system including the hydraulic-pneumatic circuit, the electronic circuit and the filling head set. The filling pump is used for fluid injection, the pressure set controls the required pressure, and the pipes and fittings are designed to carry air and other fluids. The electronic circuit includes a programmable logic controller (PLC) which supports several sensors, antilock braking system (ABS) and starter. The filling head set is mounted on the vehicles. The critical components of this set include mini-valves, pipes, couplings and sealing.

The pumps, especially the vacuum pump, operate more often and they are active in all of filling process. Therefore, they are subjected to a higher occurrence of failures. The major failure modes for pumps are filtering failure, corrosive bearing and seals failures. The main failure modes for filling 
(a)
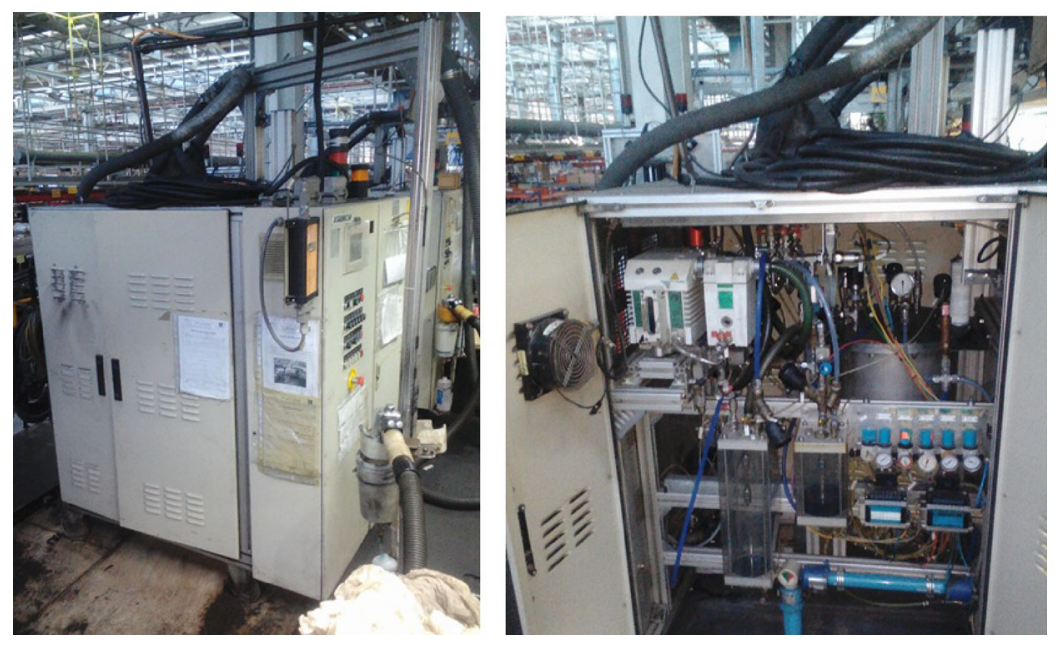

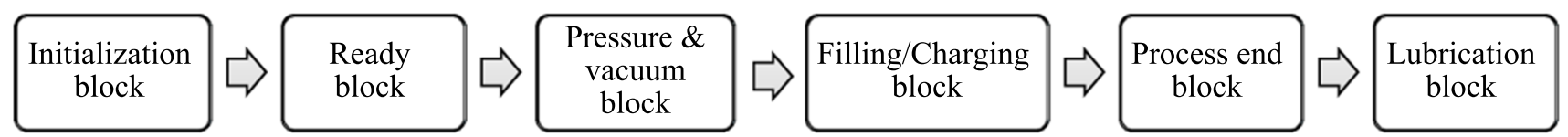

Fig. 5 Process description of the fluid filling system

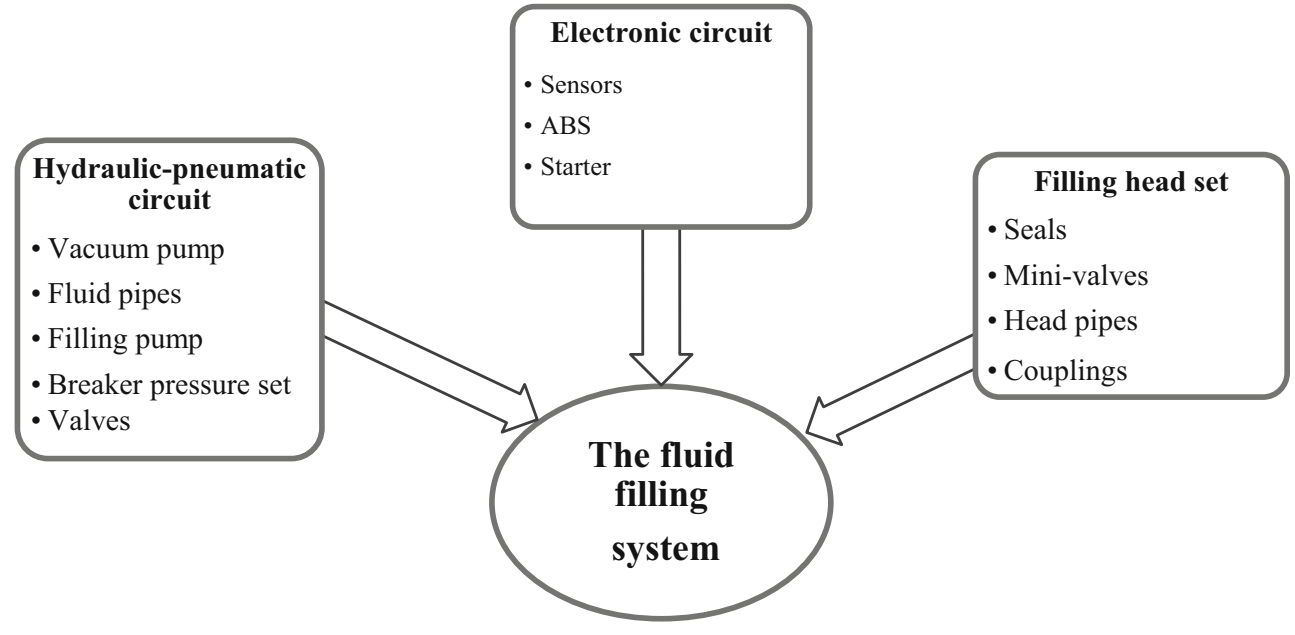

Fig. 6 The structural diagram of the fluid filling system

head set are couplings, mini-valves and seals. The failure modes for electronic circuit are sensors, ABS and starter.

According to mentioned process description, failure in fluid filling system is considered as a TE, and accordingly FT is developed illustrated in Fig. 7.

The identified $34 \mathrm{BEs}$, which contribute directly and/or indirectly to the specified TE considering common cause failures (CCFs), are shown in Table 3. To compute the FP of BEs, an expert judgment method is employed. As it mentioned earlier, in this study, because of advantages of heterogeneous group of expert to compare with homogenous one, three specialists as heterogeneous group of expert with different backgrounds was employed to compute the FP of all 34 BEs in which the qualitative terms based on experts' opinions are shown in Table 3.

Expert No. 1 A mechanical expert as a maintenance technician working in different kinds of fluid filling process with bachelor certificate.

Expert No. 2 An experienced process technician working in different kinds of process industry.

Expert No. 3 A senior fluid filling process engineer from the maintenance and operation department with master certificate. 


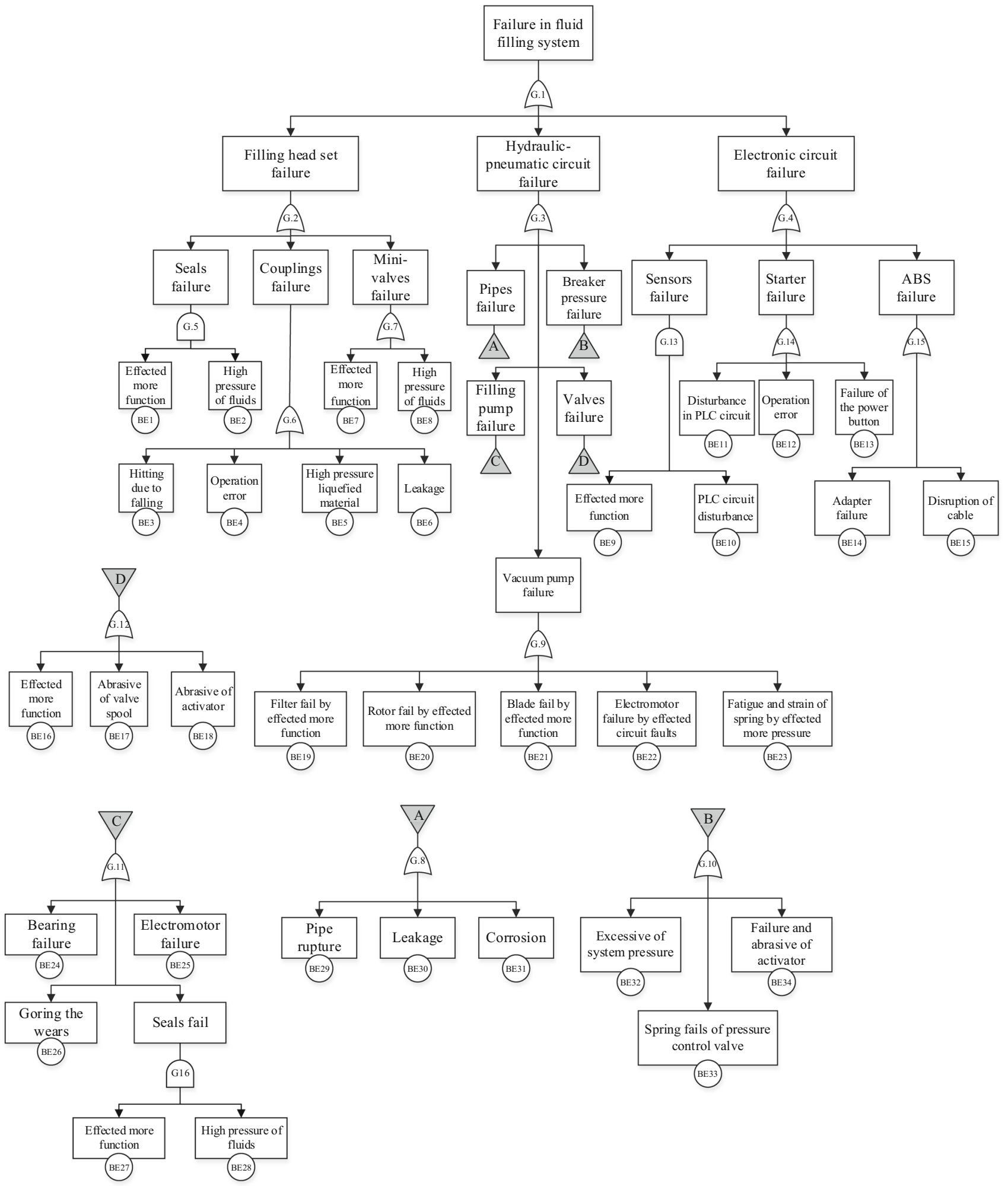

Fig. 7 Fault tree for the failure in fluid filling system

FAHP method was used to compute each expert's capability and assigning the respective weights. The system of expert information is illustrated in Fig. 8, and the expert profile and weights are shown in Table 4.
Let's take, as an example, that BE.24 "valve bearing failure". With respect to the definition of IFNs presented in Table 2 and Fig. 4, the qualitative terms, given by three 
Table 3 Details of the BEs of FT of Fig. 7

\begin{tabular}{|c|c|c|c|c|}
\hline BE tag & BEs description & Expert 1 & Expert 2 & Expert 3 \\
\hline BE.1 & Effected more function $(\mathrm{CCF})$ & $\mathrm{VH}$ & M & M \\
\hline BE.2 & High pressure of fluids (CCF) & VL & M & M \\
\hline BE.3 & Hitting due to falling & M & $\mathrm{H}$ & M \\
\hline BE.4 & Operation error (CCF) & M & $\mathrm{H}$ & VH \\
\hline BE. 5 & High pressure liquefied material & VL & M & FL \\
\hline BE.6 & Leakage (CCF) & VL & $\mathrm{VH}$ & $\mathrm{H}$ \\
\hline BE.7 & Effected more function (CCF) & FH & $\mathrm{H}$ & FL \\
\hline BE. 8 & High pressure of fluids (CCF) & FH & M & FL \\
\hline BE.9 & Effected more function $(\mathrm{CCF})$ & FL & M & M \\
\hline BE.10 & PLC circuit disturbance & FL & VL & FL \\
\hline BE.11 & Disturbance in PLC circuit & VL & VL & M \\
\hline BE.12 & Operation error $(\mathrm{CCF})$ & VL & $\mathrm{VH}$ & $\mathrm{VH}$ \\
\hline BE.13 & Failure of the power button & FL & $\mathrm{VH}$ & $\mathrm{VH}$ \\
\hline BE.14 & Adapter failure & $\mathrm{H}$ & $\mathrm{VH}$ & $\mathrm{H}$ \\
\hline BE.15 & Disruption of cable & $\mathrm{H}$ & $\mathrm{VH}$ & $\mathrm{H}$ \\
\hline BE.16 & Effected more function $(\mathrm{CCF})$ & $\mathrm{FH}$ & FL & FL \\
\hline BE.17 & Abrasive of valve spool & FL & FL & M \\
\hline BE.18 & Abrasive of activator & VL & FL & FL \\
\hline BE.19 & Filter fail by effected more function & FL & M & FL \\
\hline BE.20 & Rotor fail by effected more function & FL & FL & FL \\
\hline BE.21 & Blade fail by effected more function & FL & FL & $\mathrm{FH}$ \\
\hline BE.22 & $\begin{array}{l}\text { Electromotor failure by effected } \\
\text { circuit faults }\end{array}$ & $\mathrm{L}$ & FL & M \\
\hline BE.23 & $\begin{array}{l}\text { Fatigue and strain of spring by } \\
\text { effected more pressure }\end{array}$ & M & M & M \\
\hline BE.24 & Bearing failure & VL & FL & $\mathrm{L}$ \\
\hline BE.25 & Electromotor failure & VL & FL & FL \\
\hline BE.26 & Goring the wears & VL & FL & FL \\
\hline BE.27 & Effected more function (CCF) & VL & FL & $\mathrm{L}$ \\
\hline BE.28 & High pressure of fluids (CCF) & VL & FL & $\mathrm{L}$ \\
\hline BE.29 & Pipe rupture & VL & FL & $\mathrm{VH}$ \\
\hline BE.30 & Leakage (CCF) & FL & $\mathrm{VH}$ & M \\
\hline BE.31 & Corrosion & FL & FL & $\mathrm{FH}$ \\
\hline BE.32 & Excessive of system pressure & M & $\mathrm{L}$ & $\mathrm{FH}$ \\
\hline BE.33 & Spring fails of pressure control valve & FL & M & $\mathrm{FH}$ \\
\hline BE.34 & Failure and abrasive of activator & VL & FL & FL \\
\hline
\end{tabular}

experts, fall into "VL", "FL", and "L" categories. The integrated IFNs using Eq. 14 is attained as follows:

$$
\begin{aligned}
\alpha_{i j}^{B E_{24}}= & {\left[1-(1-0.25)^{0.327} \times(1-0.4)^{0.158}\right.} \\
& \left.\times(0.3)^{0.515},(0.7)^{0.327} \times(0.5)^{0.158} \times(0.6)^{0.515}\right] \\
& =(0.301,0.613)
\end{aligned}
$$

Using Eqs. 15 and 16, the FP of BE.24 is computed to be as:

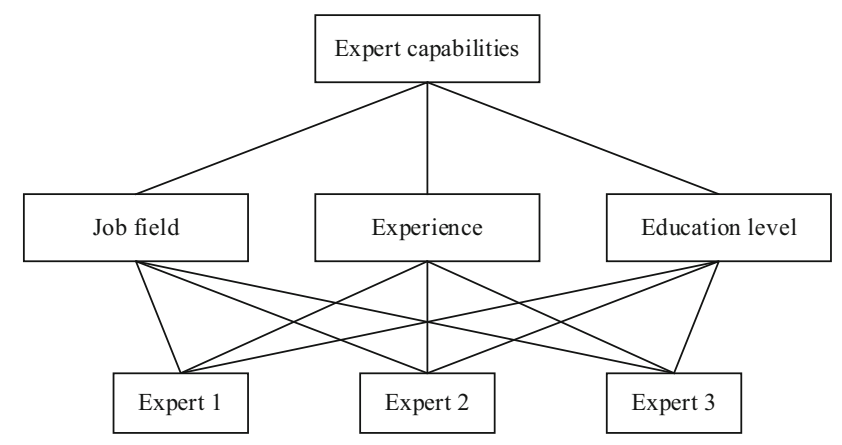

Fig. 8 Fuzzy AHP index system of respective expert capabilities 
Table 4 Experts' profile and related decision weights

\begin{tabular}{llcll}
\hline No. & Job field & Experience (years) & Education level & Weighing scores \\
\hline Expert 1 & Process operator & 10 & BSc & 0.327 \\
Expert 2 & Process technician & 2 & BSc & 0.158 \\
Expert 3 & Process engineer & 10 & MSc & 0.515 \\
\hline
\end{tabular}

Table 5 Failure probability and importance measures of the BEs based on the proposed FTA approach and the conventional approach

\begin{tabular}{|c|c|c|c|c|c|c|}
\hline \multirow[t]{2}{*}{ Tag } & \multicolumn{3}{|c|}{ Conventional approach [68] } & \multicolumn{3}{|c|}{$\begin{array}{l}\text { Proposed FTA approach based } \\
\text { on IFNs }\end{array}$} \\
\hline & $\begin{array}{l}\text { Failure } \\
\text { probability }\end{array}$ & BIM & $\overline{\text { Rank }}$ & $\begin{array}{l}\text { Failure } \\
\text { probability }\end{array}$ & BIM & Rank \\
\hline BE.1 & 0.011099337 & 0.002 & 31 & 0.01078434 & 0.002 & 32 \\
\hline BE. 2 & 0.001955927 & 0.009 & 29 & 0.00309795 & 0.009 & 29 \\
\hline BE. 3 & 0.007907948 & 0.797 & 6 & 0.00719110 & 0.799 & 12 \\
\hline BE.4 & 0.025290166 & 0.811 & 3 & 0.01884999 & 0.808 & 3 \\
\hline BE.5 & 0.000961983 & 0.791 & 23 & 0.00247050 & 0.795 & 22 \\
\hline BE.6 & 0.007588868 & 0.797 & 8 & 0.01366038 & 0.804 & 6 \\
\hline BE.7 & 0.007779303 & 0.797 & 7 & 0.00866746 & 0.800 & 8 \\
\hline BE. 8 & 0.004521893 & 0.794 & 13 & 0.00629065 & 0.798 & 15 \\
\hline BE.9 & 0.003515498 & 0.001 & 34 & 0.00448106 & 0.005 & 30 \\
\hline BE.10 & 0.000817501 & 0.003 & 30 & 0.00681942 & 0.004 & 31 \\
\hline BE.11 & 0.000531094 & 0.791 & 28 & 0.00234944 & 0.795 & 23 \\
\hline BE.12 & 0.019881110 & 0.807 & 5 & 0.01526709 & 0.805 & 5 \\
\hline BE.13 & 0.024562076 & 0.810 & 4 & 0.01825574 & 0.808 & 4 \\
\hline BE.14 & 0.042117127 & 0.825 & 1 & 0.02610237 & 0.814 & 1 \\
\hline BE.15 & 0.042117127 & 0.825 & 2 & 0.02610237 & 0.814 & 2 \\
\hline BE.16 & 0.003279533 & 0.793 & 17 & 0.00597875 & 0.798 & 16 \\
\hline BE. 17 & 0.002571485 & 0.793 & 18 & 0.00423577 & 0.796 & 18 \\
\hline BE. 18 & 0.000635664 & 0.791 & 24 & 0.00228806 & 0.795 & 26 \\
\hline BE.19 & 0.002050861 & 0.792 & 19 & 0.00369692 & 0.796 & 19 \\
\hline BE.20 & 0.001484770 & 0.792 & 21 & 0.00346594 & 0.796 & 20 \\
\hline BE. 21 & 0.004056781 & 0.794 & 15 & 0.00774903 & 0.799 & 11 \\
\hline BE.22 & 0.001694268 & 0.792 & 20 & 0.00339794 & 0.796 & 21 \\
\hline BE.23 & 0.005000345 & 0.795 & 11 & 0.00500035 & 0.797 & 17 \\
\hline BE.24 & 0.001271484 & 0.792 & 22 & 0.00140252 & 0.794 & 28 \\
\hline BE.25 & 0.000635664 & 0.791 & 26 & 0.00228806 & 0.795 & 24 \\
\hline BE.26 & 0.000635664 & 0.791 & 27 & 0.00228806 & 0.795 & 25 \\
\hline BE. 27 & 0.001271484 & 0.001 & 32 & 0.00140252 & 0.001 & 33 \\
\hline BE. 28 & 0.001271484 & 0.001 & 33 & 0.00140252 & 0.001 & 34 \\
\hline BE.29 & 0.004092129 & 0.794 & 14 & 0.01112553 & 0.802 & 7 \\
\hline BE. 30 & 0.006441994 & 0.796 & 9 & 0.00685279 & 0.798 & 14 \\
\hline BE.31 & 0.004056781 & 0.794 & 16 & 0.00774903 & 0.799 & 10 \\
\hline BE. 32 & 0.004835925 & 0.794 & 12 & 0.00717513 & 0.799 & 13 \\
\hline BE.33 & 0.005519071 & 0.795 & 10 & 0.008109160 & 0.799 & 9 \\
\hline BE.34 & 0.000635664 & 0.791 & 25 & 0.002288060 & 0.795 & 27 \\
\hline $\mathrm{TE}$ & 0.209462704 & & & 0.207039881 & & \\
\hline
\end{tabular}




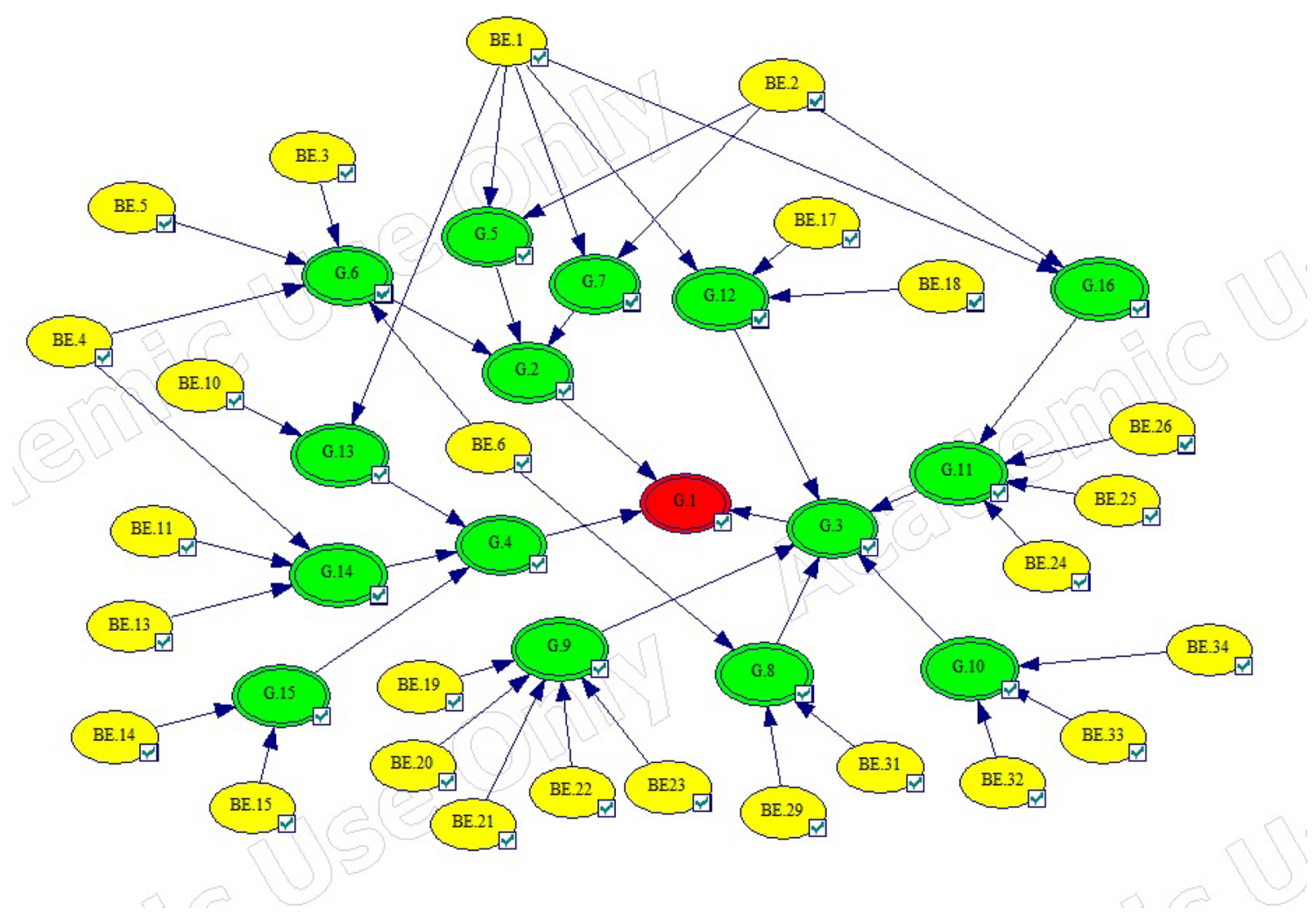

Fig. 9 Bayesian Network of the fault tree in Fig. 7

$$
\begin{aligned}
\operatorname{Val}_{S}(x) & =\frac{1}{2} \times(1+0.301-0.613)=0.344 \\
F P_{\mathrm{BE}_{24}} & =\frac{1}{10\left[\left(\frac{1}{0.344}-1\right)\right]^{1 / 3} \times 2.301}=0.00140252 .
\end{aligned}
$$

Using Eq. 17, the Birnbaum importance measure for BE.24 is computed as follows:

$I_{B E_{24}}^{B I M}=1-0.205926177=0.794$

The FP and BIM of all BEs in both conventional approach [68] and the proposed model based on IFNS are shown in Table 5.

Once the data for all BEs are obtained, the FT (Fig. 7) is mapped to a BN (Fig. 9). The prior probability values of the root nodes of the BN are defined based on the values shown in Table 3 and corresponding values provided in Table 5 in both conventional fuzzy set and IFNs. The conditional probability values of each intermediate node of the $\mathrm{BN}$ are populated based on the type of logic gate it represents. In this BN, G.1 is the node corresponds to the TE of the FT.

Now running a query on this node would return the value of system unreliability. The value of system unreliability for the system obtained from the BN model in both conventional approach and proposed approach is 0.17920899 and 0.17573203 , respectively. The system unreliability was also calculated using the conventional FT approach and new FT approach based on IFNs, and the value obtained were 0.209462704 and 0.207039881 , respectively. To compare the unreliability results, the both BN approaches are less than FT approaches. For example, the proposed BN approach is $15.12 \%$ less than the value computed by the new proposed FT based approach. In a same way, the conventional $\mathrm{BN}$ approach is $14.44 \%$ less than the value estimated by the conventional FT based approach. That is because the conventional FT approaches do not consider the statistical dependence among the events and also number of CCF are available. However, it can be seen from the $\mathrm{BN}$ model that some events are statistically dependent on each other. As an example, the events represented by nodes G.6 and G.14 are statistically dependent on each other as they share a CCF and common basic event as BE.4. For a similar reason, nodes G.5, G.7, G.12, G.13, and G.16 are also statistically dependent. The effect of these dependences also propagates through the network to the node representing the TE. As it mentioned earlier, the significant aspect of probabilistic risk assessment of a system is to determine the critical components based on their contribution to the occurrence of the system failure. This information will help to assessors and responsible decision makers to improve the system reliability by taking the necessary corrective actions or by putting more design 
Table 6 Importance measures of the BEs based on the proposed BN approach and the conventional $\mathrm{BN}$ approach

\begin{tabular}{|c|c|c|c|c|}
\hline \multirow[t]{2}{*}{ Tag } & \multicolumn{2}{|c|}{$\begin{array}{l}\text { Conventional } \\
\text { approach [75] }\end{array}$} & \multicolumn{2}{|c|}{$\begin{array}{l}\text { Proposed BN } \\
\text { approach based on } \\
\text { IFNs }\end{array}$} \\
\hline & IBM & Rank & IBM & Rank \\
\hline BE. $1,7,9,16,27$ & 0.825238 & 8 & 0.829463 & 12 \\
\hline BE. $2,8,28$ & 0.822917 & 14 & 0.827244 & 17 \\
\hline BE. 3 & 0.827334 & 5 & 0.830238 & 11 \\
\hline BE. 4,12 & 0.839757 & 4 & 0.838573 & 4 \\
\hline BE. 5 & 0.821581 & 20 & 0.826309 & 20 \\
\hline BE.6, 30 & 0.826590 & 6 & 0.832810 & 7 \\
\hline BE.10 & 0.000000 & 26 & 0.000000 & 26 \\
\hline BE.11 & 0.821227 & 25 & 0.826209 & 21 \\
\hline BE.13 & 0.841459 & 3 & 0.839595 & 3 \\
\hline BE.14 & 0.856880 & 1 & 0.846360 & 1 \\
\hline BE. 15 & 0.856880 & 2 & 0.846360 & 2 \\
\hline BE.17 & 0.822907 & 15 & 0.827774 & 15 \\
\hline BE.18 & 0.821313 & 21 & 0.826158 & 22 \\
\hline BE.19 & 0.822478 & 16 & 0.827327 & 16 \\
\hline BE.20 & 0.822012 & 18 & 0.827135 & 18 \\
\hline BE.21 & 0.824134 & 12 & 0.830705 & 10 \\
\hline BE.22 & 0.822184 & 17 & 0.827078 & 19 \\
\hline BE.23 & 0.824916 & 9 & 0.828410 & 13 \\
\hline BE.24 & 0.821836 & 19 & 0.825426 & 25 \\
\hline BE.25 & 0.821313 & 22 & 0.826158 & 23 \\
\hline BE.26 & 0.821313 & 23 & 0.826158 & 24 \\
\hline BE.29 & 0.824164 & 11 & 0.835453 & 5 \\
\hline BE.31 & 0.824134 & 13 & 0.832610 & 8 \\
\hline BE.32 & 0.824780 & 10 & 0.832129 & 9 \\
\hline BE.33 & 0.825346 & 7 & 0.832912 & 6 \\
\hline BE.34 & 0.821313 & 24 & 0.828053 & 14 \\
\hline TE probability & 0.17920899 & & 0.17573203 & \\
\hline
\end{tabular}

determinations on the feeblest part of the system. Accordingly, the safety performance of the system will be improved by facing impressive reduction in probability of TE. As an example, if the assessors want to improve the reliability of the system then they could substitute the above mentioned critical components using components with higher reliability or they could introduce redundant components in parallel with the critical components.

The criticality of the BEs of the FT and corresponding BN in Figs. 7 and 9 are computed using Eq. 17. The results of the evaluation are shown in Tables 5 and 6 for both FT and BN based approaches. According to the results shown in Table 5 which is FTA based, BE.14 (Adapter failure) contributes the most to the TE probability, thus, ranked as the most critical component. The second most critical BE is BE.15 (Disruption of cable). These failures are mainly related to electronic circuit of fluid filling system. It can be mentioned that to achieve a high reliability and safety, a parallel configuration of such components should be considered as efficiently as possible. When the both $\mathrm{BN}$ and FT ranking are compared, it is obvious that both approaches agree on the ranking of most of the components. However, there are some disagreements between the four approaches regarding the ranking of BEs. For instance, the BN-based approaches ranked BE.10 as the least critical BE whereas the conventional FT approached ranked BE. 29 and proposed FT approaches BE.28 as the least critical BE. Authors surely with high confidence believe that these differences are because of the two reasons; firstly, the statistical independence supposition of the BEs and IEs in the conventional FT approaches and secondly, due to the improving knowledge acquisition which is collated from experts using linguistic terms and their corresponding IFNs.

\section{Conclusion}

This study aimed to propose a new framework based on the 2-tuple intuitionistic fuzzy numbers to improve knowledge acquisition in failure diagnosis analysis using FTA. Bayesian network mechanism is engaged in a same way to handle the shortages of conventional FTA as well. The study results highlight an improvement in the completeness and enhancement in the probability computation for a fluid filling system fault in a production process as a case study. Additionally, comparing the results of existing techniques $[68,75]$ and the proposed approaches showed that uncertainty factors about the reliability decreases and the result are much more exact besides having improvement and progressive in knowledge acquisition. Therefore, the proposed model has following attractions to compare the conventional ones:

- The proposed model has capability of allowing the natural modeling of incomplete knowledge. The approach uses IFNs, in this way; the knowledge acquisition bottleneck can be managed.

- Fuzzy knowledge in expert systems, like human cognition and thinking, can be accustomed automatically following the changing environment through our BN model based on IFNs. This is an innovation over other models.

- Using BN has capability of letting to use historical data to update our risk analysis based on domestic information. FTA as a statistic analysis means that the assessors cannot analyze in deductive reasoning way whereas the $\mathrm{BN}$ can deal with this considerable lack.

- $\mathrm{CCF}$ and conditional dependencies between identified BEs are common fact in conventional FTA, and many methods are available like as using Beta factor to handle mentioned dependencies which seems that they are not more effective and efficient tools, whereas $\mathrm{BN}$ using conditional proba- 
bility and graphical representation has high superiority to handle dependencies.

In addition, interactive FTA suggests a process that a dynamic and mutual relation will create among all factors and parameters of risk assessment and the effects of each factor or parameters on final risk assessment will be considered. In actual fact, the key axis of the suggested approach is comprehensive interaction with all various aspects of risk assessment procedure, since the assessment problems based on decision makers' opinions have commonly multi-aspects, mostly. Therefore, the interactive approach can be able to eliminate the challenges and create the fields of sustainable risk assessment and cope with uncertainty through an effective method.

At present, we use constant amount of probability for BEs. As a direction for further studies, we plan to use Bayesian updating mechanism for adding new possible probability data. In addition, we plan to apply the proposed model in dynamic system using dynamic FTA. Maintenance optimization in terms of time and cost can be considered for future study by using Bi-objective optimization function like as [103]. The case study presented in this article provides assurance on the methodology and its competency in examining the failure of process components. Yet the current application was concentrated on automotive industry, the methodology could easily be extended to other processing systems. Furthermore, the IFNs which are used in this paper may be considered as traditional IFNs in fuzzy logic concepts. In recent years, there are many extension to IFNs have been performed like spherical IFNs which can be utilized for further studies. An argumentation on uncertainty treatment and comparing results using methods like as probability and Dempster-Shafer theory may consider for further studies.

\section{References}

1. Yazdi, M.: The application of bow-tie method in hydrogen sulfide risk management using layer of protection analysis (LOPA). J. Fail. Anal. Prev. 17, 291-303 (2017). https://doi.org/10.1007/s11 668-017-0247-x

2. Nan, C., Khan, F., Iqbal, M.T.: Real-time fault diagnosis using knowledge-based expert system. Process Saf. Environ. Prot. 86, 55-71 (2008). https://doi.org/10.1016/j.psep.2007.10.014

3. Abdo, H., Flaus, J.-M.: Monte Carlo simulation to solve fuzzy dynamic fault tree. IFAC-PapersOnLine 49, 1886-1891 (2016). https://doi.org/10.1016/j.ifacol.2016.07.905

4. Yeung, D.S., Tsang, E.C.C.: Fuzzy knowledge representation and reasoning using Petri nets. Expert Syst. Appl. 7, 281-289 (1994). https://doi.org/10.1016/0957-4174(94)90044-2

5. Constantin, C.V., Negoiță, V., Virgil, C.: Expert Systems and Fuzzy Systems. Benjamin/Cummings Pub. Co (1985). https://d 1.acm.org/citation.cfm?id=2321. Accessed 9 Mar 2018

6. Leone, N., Pfeifer, G., Faber, W., Eiter, T., Gottlob, G., Perri, S., Scarcello, F.: The DLV system for knowledge representation and reasoning. ACM Trans. Comput. Log. 7, 499-562 (2006). https:// doi.org/10.1145/1149114.1149117

7. Minker, J.: On indefinite databases and the closed world assumption. In: 6th Conference on Automated Deduction, pp. 292-308. Springer, Berlin (1982). https://doi.org/10.1007/bfb0000066

8. Chen, S.H., Jakeman, A.J., Norton, J.P.: Artificial intelligence techniques: an introduction to their use for modelling environmental systems. Math. Comput. Simul. 78, 379-400 (2008). https://d oi.org/10.1016/J.MATCOM.2008.01.028

9. Jain, S., Jain, N.K.: A generalized knowledge representation system for context sensitive reasoning: generalized HCPRs System. Artif. Intell. Rev. 30, 39-52 (2008). https://doi.org/10.1007/s104 62-009-9115-8

10. Jain, N.K., Bharadwaj, K.K., Marranghello, N.: Extended hierarchical censored production rules (EHCPRs) system: an approach toward generalized knowledge representation. J. Intell. Syst. 9, 259-295 (1999). https://doi.org/10.1515/JISYS.1999.9.3-4.259

11. Yeung, D.S., Tsang, E.C.C.: Weighted fuzzy production rules. Fuzzy Sets Syst. 88, 299-313 (1997). https://doi.org/10.1016/S0 165-0114(96)00052-8

12. Looney, C.G.: Fuzzy Petri nets for rule-based decision making. IEEE Trans. Syst. Man Cybern. 18, 178-183 (1988). https://doi. org/10.1109/21.87067

13. Polanyi, M.: The Tacit Dimension (1966). https://philpapers.org/ rec/POLTTD-2. Accessed 8 Mar 2018

14. Woo, J.H., Clayton, M.J., Johnson, R.E., Flores, B.E., Ellis, C.: Dynamic knowledge map: reusing experts' tacit knowledge in the AEC industry. Autom. Constr. 13, 203-207 (2004). https://doi.or g/10.1016/j.autcon.2003.09.003

15. Hau, Y.S., Kim, B., Lee, H., Kim, Y.G.: The effects of individual motivations and social capital on employees' tacit and explicit knowledge sharing intentions. Int. J. Inf. Manag. 33, 356-366 (2013). https://doi.org/10.1016/j.ijinfomgt.2012.10.009

16. Jasimuddin, S.M., Klein, J.H., Connell, C.: The paradox of using tacit and explicit knowledge. Manag. Decis. 43, 102-112 (2005). https://doi.org/10.1108/00251740510572515

17. Li, H., You, J.-X., Liu, H.-C., Tian, G.: Acquiring and sharing tacit knowledge based on interval 2-tuple linguistic assessments and extended fuzzy Petri nets. Int. J. Uncertain. Fuzziness Knowl. Based Syst. 26, 43-65 (2018). https://doi.org/10.1142/s0218488 518500034

18. Liu, H.-C., Liu, L., Lin, Q.-L., Liu, N.: Knowledge acquisition and representation using fuzzy evidential reasoning and dynamic adaptive fuzzy Petri nets. IEEE Trans. Cybern. 43, 1059-1072 (2013). https://doi.org/10.1109/TSMCB.2012.2223671

19. Liu, H.-C., Lin, Q.-L., Mao, L.-X., Zhang, Z.-Y.: Dynamic adaptive fuzzy Petri nets for knowledge representation and reasoning. IEEE Trans. Syst. Man Cybern. Syst. 43, 1399-1410 (2013). https://doi.org/10.1109/TSMC.2013.2256125

20. Yazdi, M.: An extension of fuzzy improved risk graph and fuzzy analytical hierarchy process for determination of chemical complex safety integrity levels. Int. J. Occup. Saf. Ergon. (2017). https://doi.org/10.1080/10803548.2017.1419654

21. Zhou, K.-Q., Zain, A.M.: Fuzzy Petri nets and industrial applications: a review. Artif. Intell. Rev. 45, 405-446 (2016). https://do i.org/10.1007/s10462-015-9451-9

22. Deng, X., Han, D., Dezert, J., Deng, Y., Shyr, Y.: Evidence combination from an evolutionary game theory perspective. IEEE Trans. Cybern. 46, 2070-2082 (2016)

23. Yan, H.S.: A new complicated-knowledge representation approach based on knowledge meshes. IEEE Trans. Knowl. Data Eng. 18, 47-62 (2006). https://doi.org/10.1109/TKDE.2006.2

24. Zadeh, L.: Fuzzy sets. Inf. Control 8, 338-353 (1965). https://do i.org/10.1109/2.53

25. Liu, H.-C., Lin, Q.-L., Wu, J.: Dependent interval 2-tuple linguistic aggregation operators and their application to multiple attribute 
group decision making. Int. J. Uncertain. Fuzziness Knowl. Based Syst. 22, 717-735 (2014). https://doi.org/10.1142/s02184885145 00366

26. Aven, T., Baraldi, P., Flage, R., Zio, E. (eds.): Uncertainty in Risk Assessment. Wiley, Chichester (2014). https://doi.org/10.1002/9 781118763032

27. Yazdi, M.: Risk assessment based on novel intuitionistic fuzzyhybrid-modified TOPSIS approach. Saf. Sci. (2018). https://doi. org/10.1016/j.ssci.2018.03.005

28. Liu, H.C., You, J.X., You, X.Y.: Evaluating the risk of healthcare failure modes using interval 2-tuple hybrid weighted distance measure. Comput. Ind. Eng. 78, 249-258 (2014). https://doi.org/ 10.1016/j.cie.2014.07.018

29. Liu, H.-C., You, J.-X., Li, P., Su, Q.: Failure mode and effect analysis under uncertainty: an integrated multiple criteria decision making approach. IEEE Trans. Reliab. 65, 1380-1392 (2016). https://doi.org/10.1109/TR.2016.2570567

30. Wan, S., Xu, G., Dong, J.: Supplier selection using ANP and ELECTRE II in interval 2-tuple linguistic environment. Inf. Sci. (Ny) 385-386, 19-38 (2017). https://doi.org/10.1016/j.ins.2016. 12.032

31. Singh, A., Gupta, A., Mehra, A.: Energy planning problems with interval-valued 2-tuple linguistic information. Oper. Res. 17, 821-848 (2017). https://doi.org/10.1007/s12351-016-0245-x

32. Shan, M.M., You, J.X., Liu, H.C.: Some interval 2-tuple linguistic harmonic mean operators and their application in material selection. Adv. Mater. Sci. Eng. (2016). https://doi.org/10.1155/2016/ 7034938

33. Lin, J., Zhang, Q., Meng, F.: An approach for facility location selection based on optimal aggregation operator. Knowl. Based Syst. 85, 143-158 (2015). https://doi.org/10.1016/j.knosys.2015. 05.001

34. Bozdag, E., Asan, U., Soyer, A., Serdarasan, S.: Risk prioritization in failure mode and effects analysis using interval type-2 fuzzy sets. Expert Syst. Appl. 42, 4000-4015 (2015). https://doi.org/1 0.1016/j.eswa.2015.01.015

35. Liu, H., Liu, L., Li, P.: Failure mode and effects analysis using intuitionistic fuzzy hybrid weighted Euclidean distance operator. Int. J. Syst. Sci. 45, 2012-2030 (2014). https://doi.org/10.1080/0 0207721.2012 .760669

36. Yazdi, M., Zarei, E.: Uncertainty handling in the safety risk analysis: an integrated approach based on fuzzy fault tree analysis. J. Fail. Anal. Prev. 18, 392-404 (2018). https://doi.org/10.1007/s11 668-018-0421-9

37. Rajakarunakaran, S., Maniram Kumar, A., Arumuga Prabhu, V.: Applications of fuzzy faulty tree analysis and expert elicitation for evaluation of risks in LPG refuelling station. J. Loss Prev. Process Ind. 33, 109-123 (2015). https://doi.org/10.1016/j.jlp.2014.11.01 6

38. Ming-Hung, S., Ching-Hsue, C., Chang, J.-R.: Using intuitionistic fuzzy sets for fault-tree analysis on printed circuit board. Assembly 46, 2139-2148 (2006). https://doi.org/10.1016/j.micro rel.2006.01.007

39. Chang, J.R., Chang, K.H., Liao, S.H., Cheng, C.H.: The reliability of general vague fault-tree analysis on weapon systems fault diagnosis. Soft. Comput. 10, 531-542 (2006). https://doi.org/10. 1007/s00500-005-0483-y

40. Cheng, S.R., Lin, B., Hsu, B.M., Shu, M.H.: Fault-tree analysis for liquefied natural gas terminal emergency shutdown system. Expert Syst. Appl. 36, 11918-11924 (2009). https://doi.org/10.1 016/j.eswa.2009.04.011

41. Kumar, M., Yadav, S.P.: The weakest t-norm based intuitionistic fuzzy fault-tree analysis to evaluate system reliability. ISA Trans. 51, 531-538 (2012). https://doi.org/10.1016/j.isatra.2012.01.004

42. M. Rausand, Risk assessment : theory, methods, and applications, J. Wiley \& Sons, 2011
43. Huang, H.Z., Zuo, M.J., Sun, Z.Q.: Bayesian reliability analysis for fuzzy lifetime data. Fuzzy Sets Syst. 157, 1674-1686 (2006). https://doi.org/10.1016/j.polymdegradstab.2005.12.004

44. Hänninen, M., Valdez Banda, O.A., Kujala, P.: Bayesian network model of maritime safety management. Expert Syst. Appl. 41, 7837-7846 (2014). https://doi.org/10.1016/j.eswa.2014.06.029

45. Bouejla, A., Chaze, X., Guarnieri, F., Napoli, A.: A Bayesian network to manage risks of maritime piracy against offshore oil fields. Saf. Sci. 68, 222-230 (2014). https://doi.org/10.1016/j.ssc i.2014.04.010

46. Khakzad, N., Khan, F., Amyotte, P.: Quantitative risk analysis of offshore drilling operations: a Bayesian approach. Saf. Sci. 57, 108-117 (2013). https://doi.org/10.1016/j.ssci.2013.01.022

47. Jensen, F.V., Nielsen, T.D.: Bayesian Networks and Decision Graphs. Springer, New York (2007). https://doi.org/10.1007/97 8-0-387-68282-2

48. Zarei, E., Azadeh, A., Aliabadi, M.M., Mohammadfam, I.: Dynamic safety risk modeling of process systems using bayesian network. Process Saf. Prog. (2017). https://doi.org/10.1002/prs.1 1889. (in press)

49. Abbassi, R., Bhandari, J., Khan, F., Garaniya, V., Chai, S.: Developing a quantitative risk-based methodology for maintenance scheduling using Bayesian network. Chem. Eng. Trans. 48, 235-240 (2016). https://doi.org/10.3303/CET1648040

50. Hashemi, S.J., Khan, F., Ahmed, S.: Multivariate probabilistic safety analysis of process facilities using the Copula Bayesian Network model. Comput. Chem. Eng. 93, 128-142 (2016). https:// doi.org/10.1016/j.compchemeng.2016.06.011

51. Yeo, C.T., Bhandari, J., Abbassi, R., Garaniya, V., Chai, S., Shomali, B.: Dynamic risk analysis of offloading process in floating liquefied natural gas (FLNG) platform using Bayesian Network. J. Loss Prev. Process Ind. 41, 259-269 (2016). https:// doi.org/10.1016/j.jlp.2016.04.002

52. Khakzad, S., Khan, F., Abbassi, R., Khakzad, N.: Accident riskbased life cycle assessment methodology for green and safe fuel selection. Process Saf. Environ. Prot. 109, 268-287 (2017). https://doi.org/10.1016/j.psep.2017.04.005

53. Khakzad, N., Reniers, G., Abbassi, R., Khan, F.: Vulnerability analysis of process plants subject to domino effects. Reliab. Eng. Syst. Saf. 154, 127-136 (2016). https://doi.org/10.1016/j.ress.20 16.06.004

54. Pereira, J.C., Fragoso, M.D., Todorov, M.G.: Risk assessment using bayesian belief networks and analytic hierarchy process applicable to jet engine high pressure turbine assembly. IFACPapersOnLine 49, 133-138 (2016). https://doi.org/10.1016/j.ifac ol.2016.07.563

55. Zarei, E., Azadeh, A., Khakzad, N., Aliabadi, M.M., Mohammadfam, I.: Dynamic safety assessment of natural gas stations using Bayesian network. J. Hazard. Mater. 321, 830-840 (2017). https:// doi.org/10.1016/j.jhazmat.2016.09.074

56. Khakzad, N., Khan, F., Amyotte, P.: Dynamic safety analysis of process systems by mapping bow-tie into Bayesian network. Process Saf. Environ. Prot. 91, 46-53 (2013). https://doi.org/10.101 6/j.psep.2012.01.005

57. Barua, S., Gao, X., Pasman, H., Mannan, M.S.: Bayesian network based dynamic operational risk assessment. J. Loss Prev. Process Ind. 41, 399-410 (2016). https://doi.org/10.1016/j.jlp.2015.11.02 4

58. Marvin, H.J.P., Bouzembrak, Y., Janssen, E.M., van der Zande, M., Murphy, F., Sheehan, B., Mullins, M., Bouwmeester, H.: Application of Bayesian networks for hazard ranking of nanomaterials to support human health risk assessment. Nanotoxicology 5390, 1-34 (2017). https://doi.org/10.1080/17435390.2016.1278 481

59. Kabir, S., Walker, M., Papadopoulos, Y.: Dynamic system safety analysis in HiP-HOPS with Petri nets and Bayesian networks. Saf. 
Sci. 105, 55-70 (2018). https://doi.org/10.1016/j.ssci.2018.02.00 1

60. Fischer, X., Nadeau, J.-P.: Interactive design: then and now. In: Research in Interactive Design, vol. 3, pp. 1-5. Springer, Paris (2011). https://doi.org/10.1007/978-2-8178-0169-8_1

61. Yazdi, M.: Improving failure mode and effect analysis (FMEA) with consideration of uncertainty handling as an interactive approach. Int. J. Interact. Des. Manuf. (2018). https://doi.org/1 0.1007/s12008-018-0496-2

62. Liu, Y., Fan, Z.P., Yuan, Y., Li, H.: A FTA-based method for risk decision-making in emergency response. Comput. Oper. Res. 42, 49-57 (2014). https://doi.org/10.1016/j.cor.2012.08.015

63. Yazdi, M., Nikfar, F., Nasrabadi, M.: Failure probability analysis by employing fuzzy fault tree analysis. Int. J. Syst. Assur. Eng. Manag. 8, 1177-1193 (2017). https://doi.org/10.1007/s13198-01 7-0583-y

64. Guan, Y., Zhao, J., Shi, T., Zhu, P.: Fault tree analysis of fire and explosion accidents for dual fuel (diesel/natural gas) ship engine rooms. J. Mar. Sci. Appl. 15, 331-335 (2016). https://doi.org/10. 1007/s11804-016-1366-6

65. M. Rausand, Reliability of safety-critical systems, 2014

66. Kabir, S.: An overview of fault tree analysis and its application in model based dependability analysis. Expert Syst. Appl. 77, 114-135 (2017). https://doi.org/10.1016/j.eswa.2017.01.058

67. Ferdous, R., Khan, F., Sadiq, R., Amyotte, P., Veitch, B.: Fault and event tree analyses for process systems risk analysis: uncertainty handling formulations. Risk Anal. 31, 86-107 (2011). https://do i.org/10.1111/j.1539-6924.2010.01475.x

68. Yazdi, M.: Hybrid probabilistic risk assessment using fuzzy FTA and fuzzy AHP in a process industry. J. Fail. Anal. Prev. 17, 756-764 (2017). https://doi.org/10.1007/s11668-017-0305-4

69. Smith, D., Veitch, B., Khan, F., Taylor, R.: Understanding industrial safety: comparing fault tree, Bayesian network, and FRAM approaches. J. Loss Prev. Process Ind. 45, 88-101 (2017). https:// doi.org/10.1016/j.jlp.2016.11.016

70. Adedigba, S.A., Khan, F., Yang, M.: Dynamic failure analysis of process systems using principal component analysis and Bayesian network. Ind. Eng. Chem. Res. 56, 2094-2106 (2017). https://do i.org/10.1021/acs.iecr.6b03356

71. Xin, P., Khan, F., Ahmed, S.: Dynamic hazard identification and scenario mapping using Bayesian network. Process Saf. Environ. Prot. 105, 143-155 (2017). https://doi.org/10.1016/j.psep.2016.1 1.003

72. Chiremsel, Z., Said, R.N., Chiremsel, R.: Probabilistic fault diagnosis of safety instrumented systems based on fault tree analysis and Bayesian network. J. Fail. Anal. Prev. 16, 747-760 (2016). https://doi.org/10.1007/s11668-016-0140-Z

73. Zhang, C., Wei, Y., Li, Z., Zhao, Y.: Hazard-based design of the bow-tie method to prevent and mitigate mine accidents. J. Fail. Anal. Prev. (2017). https://doi.org/10.1007/s11668-017-0367-3

74. Chang, Y., Chen, G., Wu, X., Ye, J., Chen, B., Xu, L.: Journal of loss prevention in the process industries failure probability analysis for emergency disconnect of deepwater drilling riser using Bayesian network. J. Loss Prev. Process Ind. 51, 42-53 (2018). https://doi.org/10.1016/j.jlp.2017.11.005

75. Yazdi, M., Kabir, S.: A fuzzy Bayesian network approach for risk analysis in process industries. Process Saf. Environ. Prot. 111, 507-519 (2017). https://doi.org/10.1016/j.psep.2017.08.015

76. Ford, D.N., Sterman, J.D.: Expert knowledge elicitation to improve formal and mental models. Syst. Dyn. Rev. 14, 309-340 (1998). https://doi.org/10.1002/(SICI)1099-1727(199824)14:4< 309::AID-SDR154>3.0.CO;2-5

77. Yazdi, M., Daneshvar, S., Setareh, H.: An extension to fuzzy developed failure mode and effects analysis (FDFMEA) application for aircraft landing system. Saf. Sci. 98, 113-123 (2017). https://doi.org/10.1016/j.ssci.2017.06.009
78. Helvacioglu, S., Ozen, E.: Fuzzy based failure modes and effect analysis for yacht system design. Ocean Eng. 79, 131-141 (2014). https://doi.org/10.1016/j.oceaneng.2013.12.015

79. Saaty, T.L.: Creative Thinking, Problem Solving and Decision Making. RWS Publications, Pittsburgh (2010)

80. Guneri, A.F., Gul, M., Ozgurler, S.: A fuzzy AHP methodology for selection of risk assessment methods in occupational safety. Int. J. Risk Assess. Manag. 18, 319 (2015). https://doi.org/10.15 04/IJRAM.2015.071222

81. Buckley, J.J.: Fuzzy hierarchical analysis. Fuzzy Sets Syst. 17, 233-247 (1985). https://doi.org/10.1016/0165-0114(85)90090-9

82. Chang, D.-Y.: Applications of the extent analysis method on fuzzy AHP. Eur. J. Oper. Res. 95, 649-655 (1996). https://doi.org/10.1 016/0377-2217(95)00300-2

83. Atanassov, K.T.: Intuitionistic fuzzy sets. Fuzzy Sets Syst. 20, 87-96 (1986). https://doi.org/10.1016/S0165-0114(86)80034-3

84. Xu, Z.: Approaches to multiple attribute group decision making based on intuitionistic fuzzy power aggregation operators. Knowl. Based Syst. 24, 749-760 (2011). https://doi.org/10.1016/j.knosy s.2011.01.011

85. Chang, K.-H., Cheng, C.-H.: A risk assessment methodology using intuitionistic fuzzy set in FMEA. Int. J. Syst. Sci. 41, 1457-1471 (2010). https://doi.org/10.1080/00207720903353633

86. Chang, K.H., Cheng, C.H., Chang, Y.C.: Reprioritization of failures in a silane supply system using an intuitionistic fuzzy set ranking technique. Soft. Comput. 14, 285-298 (2010). https://do i.org/10.1007/s00500-009-0403-7

87. Atanassov, K.T.: On the concept of intuitionistic fuzzy sets. In: 2012, pp. 1-16. https://doi.org/10.1007/978-3-642-29127-2_1

88. Liu, H., You, J., Shan, M., Shao, L.: Failure mode and effects analysis using intuitionistic fuzzy hybrid TOPSIS approach. Soft Comput. 19, 1085-1098 (2015). https://doi.org/10.1007/s00500014-1321-x

89. Szmidt, E.: Introduction. In: Distances and similarities in intuitionistic fuzzy sets. Studies in Fuzziness and Soft Computing, vol. 307. Springer, Cham (2014)

90. Xu, Z., Yager, R.R.: Some geometric aggregation operators based on intuitionistic fuzzy sets. Int. J. Gen. Syst. 35, 417-433 (2006). https://doi.org/10.1080/03081070600574353

91. Wang, W., Liu, X.: Intuitionistic fuzzy information aggregation using einstein operations. IEEE Trans. Fuzzy Syst. 20, 923-938 (2012). https://doi.org/10.1109/TFUZZ.2012.2189405

92. Xu, Z., Zhao, N.: Information fusion for intuitionistic fuzzy decision making: an overview. Inf. Fusion 28, 10-23 (2016). https:// doi.org/10.1016/j.inffus.2015.07.001

93. Xu, Z.: Intuitionistic fuzzy aggregation operators. IEEE Trans. Fuzzy Syst. 15, 1179-1187 (2007)

94. Zeng, S.: The intuitionistic fuzzy ordered weighted averagingweighted average operator and its application in financial decision making. World Acad. Sci. Eng. Technol. 6, 541-547 (2012)

95. Boran, F.E., Genç, S., Kurt, M., Akay, D.: A multi-criteria intuitionistic fuzzy group decision making for supplier selection with TOPSIS method. Expert Syst. Appl. 36, 11363-11368 (2009). https://doi.org/10.1016/j.eswa.2009.03.039

96. Anzilli, L., Facchinetti, G.: A New Proposal of Defuzzification of Intuitionistic Fuzzy Quantities, pp. 185-195. Springer, Cham (2016). https://doi.org/10.1007/978-3-319-26211-6_16

97. Onisawa, T.: Subjective analysis of system reliability and its analyzer. Fuzzy Sets Syst. 83, 249-269 (1996). https://doi.org/10.10 16/0165-0114(95)00381-9

98. Onisawa, T.: A representation of human reliability using fuzzy concepts. Inf. Sci. (Ny) 45, 153-173 (1988). https://doi.org/10.1 016/0020-0255(88)90038-2

99. Kabir, S., Yazdi, M., Aizpurua, J.I., Papadopoulos, Y.: Uncertainty-aware dynamic reliability analysis framework for 
complex systems. IEEE Access. 6, 29499-29515 (2018). https:// doi.org/10.1109/ACCESS.2018.2843166

100. Vesely, W.E., Stamatelatos, M., Dugan, J., Fragola, J., Minarick, J.,Railsback, J. : Fault tree handbook with aerospace applications (2002)

101. Cheok, M.C., Parry, G.W., Sherry, R.R.: Use of importance measures in risk-informed regulatory applications. Reliab. Eng. Syst. Saf. 60, 213-226 (1998). https://doi.org/10.1016/S0951-8320(97 )00144-0

102. Yazdi, M., Korhan, O., Daneshvar, S.: Application of fuzzy fault tree analysis based on modified fuzzy AHP and fuzzy TOPSIS for fire and explosion in process industry. Int. J. Occup. Saf. Ergon. (2018). https://doi.org/10.1080/10803548.2018.1454636
103. Nedjati, A., Izbirak, G., Arkat, J.: Bi-objective covering tour location routing problem with replenishment at intermediate depots: formulation and meta-heuristics. Comput. Ind. Eng. 110, 191-206 (2017). https://doi.org/10.1016/J.CIE.2017.06.004

Publisher's Note Springer Nature remains neutral with regard to jurisdictional claims in published maps and institutional affiliations. 